\title{
Fincas mayores en la provincia de Jaén 1979 Estructuras regionales y agrarias del mediano y gran latifundio en una fase de cambio radical en España*
}

\author{
Larger estates in the province of Jaén in 1979 \\ Regional agricultural structures of medium-sized and \\ large estates in a period of radical change in Spain
}

\author{
Konrad Tyrakowski Findeiss**
}

\section{EL OBJETIVO DEL ESTUDIO}

El periodo entre 1975 y 1986 significó para España una cesura importante: en 1975 terminaba la dictadura de Franco y en 1986 España se convertía en miembro de la Comunidad Europea (CE). Con dicho acontecimiento, los fundamentos hasta aquel entonces vigentes de la situación socioeconómica española cambiaron. Principalmente, la agricultura empezó a perder más y más la importancia que hasta la fecha había tenido, sobre todo en las regiones periféricas. En Andalucía, la provincia de Jaén era tradicionalmente un espacio muy pobre, un espacio discriminado por su marginal situación interna, por sus deficientes condiciones físico-geográficas, sus señoriales títulos de propiedad, sus mono-estructuras agrarias, un espacio que aún poseía unas actividades bastante atrasadas en lo que se refiere a la industria y la artesanía.

* El autor agradece a la señorita Eva Olmo Gil, de Puertollano, doctoranda en geografía física de la Universidad de Eichstaett-Ingolstadt, la supervisión de la traducción.

** Lehrstuhl für Kulturgeographie, Katholische Universität Eichstätt-Ingolstadt. Alemania (konrad.tyrakowski@ku-eichstaett.de). 
Nacional y regionalmente, la distribución de la propiedad era considerada injusta y fue un tema por aquel entonces, e incluso hoy, muy discutido. De esta forma, Pascual Carrión Carrión (1975) convirtió el tema del latifundismo en uno de los más importantes de la España de entonces; porque se percibía en el latifundio dominante la causa principal de la pobreza regional. Sobre ese tema Higueras Arnal (1961, pp. 127-130) realizó un estudio geográfico en el que planteo el problema de la distribución de la tierra en la provincia de Jaén.

Desde la antigüedad, Andalucía ha sido siempre una región caracterizada por el latifundio, y su estructura agraria ha sido descrita y analizada recientemente por un gran número de trabajos, por ejemplo los de Guarnido Olmedo et al. (1976a, 1976b), Gómez Jover (1974), Artola et al. (1978), Mata Olmo (198111, 1987), Quirós Romero (1984, pp. 79-93), Sánchez Salazar (1984), Araque Jiménez (1991), Fundación «Estrategias para el desarrollo económico y social de la provincia de Jaén» (2001), Villalba Cabello (coord.) (2000), Cobo Romero y Ortega López (2005).

Varios intentos de reforma agraria organizados por el Estado entre 1953 y 1980 pretendieron zanjar el abismo existente entre latifundio y el campesino con minifundio o «sin tierra». Aunque este intento fue poco exitoso (Araque Jiménez 1983, Tyrakowski 1987, 1993, 1995), después de la entrada de España en la CE parecía que el fin de la cuestión agraria había llegado. Pero ya por aquel entonces Malefakis (El País 29.2.1984) opinó que el futuro de Andalucía no se basaría en la agricultura, aunque fuera en ella donde se llegara a una repartición de tierra justa, razonable y no-utópica (Quirós Romero, 1984, p. 172)2. En cuanto a la estructura organizada y económica de la mediana y gran propiedad de la tierra, existían en la literatura algunas expresiones pesimistas sobre el desarrollo deficiente del espacio agrario y del sistema capitalista de los terratenientes (García de Cortázar y González Vesga, 1994, pp. 468-470; Cobo Romero y Ortega López, 2005, p. 29). La estima de los campesinos por el latifundio la expresa Gómez Jover (1974, p. 224) con las siguientes palabras: «... para el campesino andaluz tiene un doble significado de admiración y rencor, con un predominio sin duda alguna de este último...».

\footnotetext{
${ }^{1}$ El estudio de Mata Olmo fue publicado en 1981, sin embargo el texto está basado en un censo más antiguo de 1964 (op. cit., p. 141).

2 También en Extremadura se discutió durante mucho tiempo la cuestión agraria y en esa región la expropiación de tierras tuvo una gran repercusión (El País 31.1.1999).
} 
Constantemente se ha mencionado en la literatura los siguientes puntos negativos de la estructura agraria andaluza:

- Las desventajas de la desproporción de la propiedad de la tierra.

- El desinterés de los latifundistas por sus predios y consecuentemente su ausencia de la finca.

- El uso extensivo poco rentable de las fincas grandes.

- La acumulación de tierras como inversión de capitales en círculos sociales de la gran burguesía.

- La formación de una oligarquía potente de terratenientes nobles y grandes burgueses.

- La dominación por el mercado de trabajo y por ende la proletarización de los jornaleros.

Principalmente en la provincia de Jaén, se estimó el dualismo entre latifundio y minifundio, el monocultivo del olivar y el escaso interés por la intensificación de los grandes terratenientes como causas principales del paro y de la pobreza (Maurice, 1975, pp. 2-5; Guarnido Olmedo et al., 1976b, pp. 85-91). Esta opinión parecía tener confirmación en los flujos de emigrantes a Francia y Alemania entre 1960 y 1975. Por ello, el interés inicial de los simples grupos agro-sociales por la reforma agraria durante el «Plan Jaén» a partir de 1953 respondió a esa experiencia de pauperización (Tyrakowski, 1987)3.

Las diferentes propiedades territoriales tuvieron varios orígenes: durante y tras la Reconquista, los reyes repartieron tierras como retribución por sus servicios militares a nobles, municipios e iglesia. En el mosaico de la pequeña y la gran propiedad en la provincia de Jaén, fue característico que en el tercio occidental dominaran las órdenes militares ${ }^{4} \mathrm{y}$ la iglesia, y en los tercios medio y oriental de la provincia prevaleciesen las tierras de realengo y de la nobleza. En el transcurso del tiempo, algunas sociedades eclesiásticas recibieron grandes propiedades de tierra, de las cuales amplias porciones estuvieron desaprovechadas. En el siglo xIx, la monarquía $(1805,1806)$ y los gobiernos liberales

3 Todavía en 1990 hubo quejas respecto a las condiciones inhumanas de vida en más de los 10.000 jornaleros en la cosecha de aceitunas; con lo que se llegaron a multar hasta 102 cortijos (El País 26.6.1990).

${ }^{4}$ Principalmente desde los siglos XIII hasta XVI, la Orden de Calatrava, en el oeste de la provincia, y la Orden de Santiago, en la parte media así como en el oriente, fueron recompensadas con tierras y derechos fiscales (Artola et al. 1978, anexo; Rodríguez Molina, 1974-1975). Este hecho lo recuerdan los nombres de dos municipios occidentales: Higuera de Calatrava y Santiago de Calatrava. Dichas órdenes también supieron prevenir que la nobleza secular no pudiera extenderse por la provincia durante los siglos XIV y XV (Mata Olmo, 1981, p. 142). 
(1820-1823, 1836-1837, 1841-1843, 1854-1856) llevaron de nuevo a cabo cambios en la propiedad de los bienes inmuebles por subastas y ventas (desamortizaciones) y por disolución de los mayorazgos de la nobleza agraria: con ello se intentó terminar con el «despilfarro de tierras» de la «mano muerta» de municipios e iglesias. Esas tierras llegaron a manos de la nobleza y círculos ciudadanos (nobleza del dinero, empresarios agrarios burgueses, grandes comerciantes, profesionales liberales), pero también a las de los empresarios campesinos y los pequeños burgueses (Mata Olmo, II, 1987, pp. 32, 35-36). La crisis agraria a principios del siglo xx influyó además en la alimentación del mercado con la masiva venta de tierras (García de Cortázar et al., 1994, p. 464-470). Estos cambios en la estructura de la propiedad han sido típicos en Andalucía, con lo cual Jaén llegó en un obligado ranking del valor comercial a la cuarta posición después de Sevilla, Córdoba y Cádiz (Artillo González, 1982, pp. 410-413).

En las páginas siguientes se realizará un análisis del orden estructural del mediano y gran latifundio existente en la provincia de Jaén en 1979. Se explicará cómo transcurrió la transición de la época franquista al período en el que España llegó a ser socio de la CE, y cómo se desarrolló el aprovechamiento de las tierras jiennenses estadísticamente, a fin de que las preconcepciones mencionadas puedan ser aceptadas o rechazadas.

Los datos se obtuvieron a partir de una estadística especial ${ }^{5}$ del Instituto Nacional de Reforma y Desarrollo Agrario (IRYDA) cuyo objetivo concreto es desconocido, pero que pudiera ser interpretado. Podría haberse tratado de conocer los niveles del uso económico a fin de aclarar qué fincas ${ }^{6}$ podrían aprovecharse mejor. Para ello, esta estadística se refiere a las siguientes materias:

- afiliación municipal

- nombre de la finca

- total de la superficie útil

- uso

- regadío, huerta

- cereal secano

- olivar riego

${ }^{5}$ La estadística del año 1979, se denomina «Relación de Fincas de mediana y gran extensión de la provincia de Jaén. Estado actual de cultivo y aprovechamiento», citada en adelante como «Relación». El autor agradece al sr. Wolfgang Vorliczky, profesor de instituto, su atenta colaboración en la calculación computerizada de los datos.

${ }^{6}$ Una finca es una propiedad de terreno acotada o una parte cerrada de aquella en la cual puede existir un cortijo. Dicha investigación podría haber sido producida bajo la observación de la «Ley de Comarcas y Fincas Mejorables» de 1971 y de la «Ley de Reforma y Desarrollo Agrarios» de 1973. 
- olivar secano

- monte y pastos

- pinar

- propietario

- domicilio

- observaciones respecto a organización e intensidad del uso.

Esta estadística es incompleta, porque contiene solamente datos de $79 \mathrm{mu}$ nicipios (figura 1), mientras que en la provincia de Jaén existían exactamente 96 municipios $^{7}$. De todos modos tenemos datos de 507 empresas de mediana o gran superficie útil que para 1979 aportan ciertas evaluaciones positivas.

\section{INTENTOS DE DEFINIR EL LATIFUNDIO}

La definición de la pequeña, mediana y gran propiedad es difícil. Principalmente hay que tener en cuenta el momento histórico de observación, la evaluación de la situación físiogeográfica regional, el tipo de cultivo, la inversión de capitales, los ingresos netos, etc., para la definición de dichas categorías. Por la estadística, se obtiene la mejor asequibilidad calculándose principalmente a partir del tamaño de la superficie agraria. Sin embargo, la mayor dificultad se produce cuando intentamos encontrar en el continuo desde el minifundio al latifundio los valores umbral operativos en una región definida. No hay una definición teórica ni práctica clara y duradera de lo que podemos llamar «gran propiedad». La tabla 1 muestra cómo las diferentes definiciones dependen mucho del momento histórico del que se trata, de la región geográfica y finalmente de las ideas estándar predominantes en el momento ${ }^{8}$. En el estudio presente y con base en la literatura consultada, el tema en cuestión en 1979, las características de la región geográfica del Alto Guadalquivir y la situación tecnológica de entonces, se ha fijado como pequeña propiedad extensiones de hasta $20 \mathrm{ha}^{9}$, mediana propiedad la comprendida entre 21 y 200 ha y los latifundios a partir de las 200 ha.

${ }^{7}$ La causa del levantamiento incompleto es desconocida, pero podría estar relacionada con el hecho de que en el resto de los municipios dominaba la pequeña propiedad.

8 Sevilla-Guzmán (1979, pp. 192-201) examinó críticamente la definición de Carrión (1975, pp. 71-76) con su distinción de función social y función económica.

9 Para completar la definición debe ser anotado que la pequeña propiedad no tiene únicamente como especial característica el tamaño reducido, sino también una gran parcelación y disgregación (Sevilla-Guzmán, 1979, pp. 264-265). 
TABLA 1

CLASIFICACIÓN DE PROPIEDADES SEGÚN VARIOS AUTORES

\begin{tabular}{|c|c|c|c|c|c|}
\hline Autores & $\begin{array}{c}\text { CARRIÓN }\left(1975^{2} \text {, }\right. \\
\text { pp. } 81-83)\end{array}$ & $\begin{array}{l}\text { HigUERAS ARNAL } \\
(1961, \text { p. 128) }\end{array}$ & $\begin{array}{c}\text { Mata Olmo }(1981, \\
\text { pp. } 140,142)\end{array}$ & $\begin{array}{l}\text { ARAQUE JIMENEZ } \\
(1991, \text { p. } 24)\end{array}$ & $\begin{array}{c}\text { García } \\
\text { Torrente } \\
(2005, \text { p. } 161)\end{array}$ \\
\hline $\begin{array}{l}\text { Región } \\
\text { geográfica }\end{array}$ & Sur de España & Alto Guadalquivir & Campiña de Jaén & $\begin{array}{l}\text { Provincia } \\
\text { de Jaén }\end{array}$ & $\begin{array}{l}\text { Provincia de } \\
\text { Almería }\end{array}$ \\
\hline Minifundio & $\begin{array}{l}\text { Fincas menores } \\
\text { de } 10 \text { ha }\end{array}$ & $\begin{array}{l}\text { Propietarios con } \\
\text { menos de } 10 \text { ha }\end{array}$ & $\begin{array}{l}\text { Pequeña propiedad: } \\
\text { explotaciones } \\
\text { menores de } 30 \text { ha }\end{array}$ & $\begin{array}{l}\text { Explotaciones } \\
\text { comprendidas } \\
\text { entre } 0,1 \text { y } 5 \text { ha }\end{array}$ & $\begin{array}{l}\text { por debajo de } \\
\text { las } 5 \text { ha de } \\
\text { SAU }\end{array}$ \\
\hline $\begin{array}{l}\text { Grupo } \\
\text { intermedio }\end{array}$ & $\begin{array}{l}\text { Medianas fincas } \\
\text { de } 10 \text { a } 100 \text { ha }\end{array}$ & $\begin{array}{l}\text { Entre } \\
\text { latifundistas y } \\
\text { minifundistas }\end{array}$ & $\begin{array}{l}\text { «campesinos } \\
\text { acomodados» o } \\
\text { «campesinos } \\
\text { capitalistas» con } \\
50-100 \text { ha }\end{array}$ & $\begin{array}{l}\text { Explotaciones } \\
\text { comprendidas } \\
\text { entre } 5 \text { y } 200 \text { ha }\end{array}$ & $\begin{array}{l}\text { [entre } 5 \mathrm{y} \\
100 \mathrm{ha}]\end{array}$ \\
\hline Latifundio & $\begin{array}{l}\text { fincas con más } \\
\text { de } 250 \text { ha }\end{array}$ & $\begin{array}{l}\text { propietarios de } \\
\text { más de } 500 \text { ha }\end{array}$ & $\begin{array}{l}\text { Grandes } \\
\text { propiedades- } \\
\text { explotaciones con } \\
\text { superficie olivarera } \\
\text { de } 90 \text { a } 110 \text { ha, a } \\
\text { partir de } 10.000 \\
\text { olivos }\end{array}$ & $\begin{array}{l}\text { propiedades } \\
\text { con más de } \\
200 \text { ha }\end{array}$ & $\begin{array}{l}\text { Una dimensión } \\
\text { superior a las } \\
100 \text { ha de } \\
\text { SAU* }^{*}\end{array}$ \\
\hline
\end{tabular}

* SAU = superficie agrícola utilizada: toda la propiedad de la finca exceptuando pinar, monte y pastos.

El ESPACIO NATURAL DE LA PROVINCIA DE JAÉN

La provincia está definida por el Alto Guadalquivir. En este territorio podemos encontrar un relieve acentuado y valles angostos. Las grandes áreas de terrazas fluviales únicamente se encuentran en la parte occidental de la provincia. Característica es la yuxtaposición de vegas bajas (300-500 m de altitud), medianas alturas $(500-800 \mathrm{~m}$ ) y posiciones altas (hasta más de 2.000 $\mathrm{m})$. La Campiña, acompañada y regada por el río, desciende hacia poniente y está fuertemente modelada en las áreas cercanas al curso del río. En oriente, sin embargo, la llanura se estrecha y se descompone en vegas delgadas que como dedos penetran en los valles laterales y forman el valle cerrado dispuesto entre las sierras Morena, Segura, Cazorla y Mágina con alturas superiores a $2.000 \mathrm{~m}$. Entre ellas se encuentran cadenas de lomas margosas y cerros como mesetas con sus llanuras de piedemonte. 
En las mayores alturas se producen tan sólo 2-3 meses áridos: la ventaja hídrica resulta de las fuertes lluvias invernales que traen al círculo serrano entre 500 y $1.200 \mathrm{~mm}$ de precipitaciones. En verdad, las zonas bajas reciben menos de $500 \mathrm{~mm}$ y la evaporación potencial con $1.000 \mathrm{~mm}$ supera con mucho la precipitación normal. El mosaico de los suelos es muy variado: sobre la loma central de Baeza-Úbeda se encuentra un tipo de rendzina fértil y profunda. La Campiña muestra xerorendzinas con poco humus, las terrazas del Guadalquivir contienen limo rojo y grandes campos de cantos rodados. Suelos esqueléticos se extienden sobre las pizarras paleozoicas de la Sierra Morena. En definitiva, altitud, topografía y suelos juegan un papel importante en los usos agrícolas y en sus resultados.

\section{PANORAMA ESTADÍSTICO DE LA GRAN PROPIEDAD EN 1979}

En la estructura agraria de la provincia de Jaén es importante destacar que alrededor de 1980 existía una importante pequeña propiedad ( $\leq 1-20 \mathrm{ha}=85,2 \%$ de todas las empresas) junto a una reducida gran propiedad ( $\geq 100 \mathrm{ha}=7,02 \%$ de todas las empresas) muy fuerte en capitales (Quiroz Romero, 1984, pp. 83-84). En 1999 había 96.658 empresas (INE 2002b), de las que un 93,51\% correspondía a pequeñas empresas ( $\leq 1-20 \mathrm{ha}$ ) y un $1,01 \%$ a latifundios $(100-\geq 500 \mathrm{ha})^{10}$. Con este contraste según el número de empresas, Jaén se situaba en primer lugar de entre todas las provincias andaluzas (INE 2002a). La cuestión del laboreo intensivo o extensivo tuvo mucho interés por lo que la «Relación» de 1979 ofrecía los tipos de cultivos y de aprovechamientos. Se estableció que del total de 493 fincas, trece se encontraban subdivididas ${ }^{11}$, de modo que, al fin, se consideraron 507 fincas. El total de los empresarios entrevistados trabajaba una superficie útil de 322.754 ha, equivalente al 46,06\% de la extensión útil provincial, 700.493 ha en 1974 (según Araque Jiménez, 1983, p. 160).

\section{Categorías de las extensiones}

También la estructura de las 507 fincas analizadas muestra una diferenciación clara entre propiedades mayores y menores. Casi en tres cuartas partes domina la superficie del latifundio con más de 200 ha, entre las cuales las fin-

\footnotetext{
${ }^{10}$ Clasificación de las fincas según Superficie Agrícola Utilizada (SAU).

1112 fincas estaban divididas en 2 empresas cada una, y otra (la número 13) estaba a su vez subdividida en 3 partes que se trabajaban a la vez desde el «cortijo-madre».
} 
cas entre 201 y 500 ha tienen la mayor fracción con un 46,75\%. Su extensión total supone casi el doble que la de las grandes propiedades con más de 500 ha. Pero hay que tener en cuenta que entre las últimas, la superficie de uso extensivo, utilizada como pasto, monte y pino, ocupa una gran porción del territorio.

TABLA 2

CLASES DE FINCAS ENCUESTADAS EN LA PROVINCIA DE JAÉN 1979

\begin{tabular}{ccccc}
\hline $\begin{array}{c}\text { Clases según } \\
\text { tamaño en ha }\end{array}$ & Cantidad & en \% & Superfície total en ha & en \% \\
\hline $20-50$ & 3 & 0,59 & 150 & 0,06 \\
$51-100$ & 33 & 6,51 & 2.284 & 0,70 \\
$101-200$ & 51 & 10,06 & 7.885 & 2,40 \\
$201-500$ & 237 & 46,75 & 78.472 & 23,90 \\
$501-1000$ & 113 & 22,29 & 77.557 & 23,90 \\
$>1000$ & 70 & 13,81 & 156.406 & 49,10 \\
Suma & 507 & 100,00 & 322.754 & 100,00 \\
\hline
\end{tabular}

Fuente: «Relación» 1979.

\section{La distribución regional}

El panorama de las superficies utilizadas en la «Relación» de 1979 ofrece lagunas marcadas, sin una clara disposición de datos. A pesar de ello, se pueden reconocer elementos fundamentales de la distribución (figura 1). Las extensiones de mediana y gran propied se encuentran dentro de Sierra Morena. Es en este territorio donde las condiciones físicas de gran sequía y suelos pobres demandan grandes extensiones de territorio. Además, en las sierras tanto orientales como meridionales de Segura, Cazorla, Quesada y Pandera existen fincas de gran extensión. Este hecho coincide con las indicaciones de Guarnido Olmedo (1976b, pp. 57, 59). Claramente se levanta en medio de la provincia la gran loma de Baeza-Úbeda con sus unidades de gran extensión. A ambos lados de esta loma, de forma más evidente en el noroeste y menos destacada en el sur, se encuentran municipios pequeños con una mayor proporción de propiedades pequeñas. En el norte, esos municipios se orientan a lo largo del eje del río Guadalquivir y en el oriente y el sur ocupan las cuencas 
FIGURA 1

JAÉN: SUPERFICIE TOTAL DE EXPLOTACIONES MAYORES POR MUNICIPIO 1979

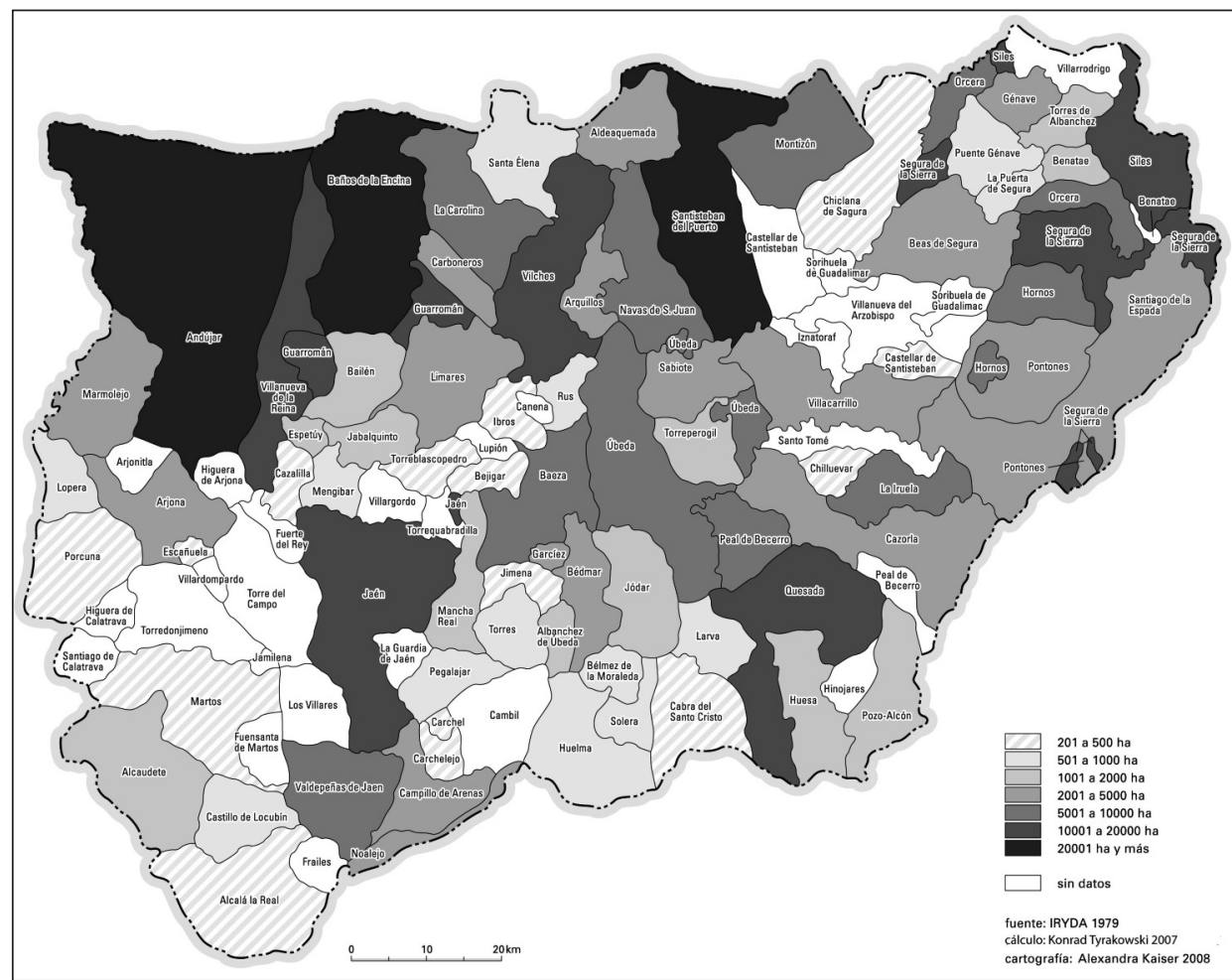

intramontanas $\mathrm{u}$ hondonadas. Finalmente, la topografía participa fuertemente en la distribución de las diferentes categorías de propiedades.

\section{Tamaño y uso de las fincas}

Como la tabla 3 muestra, las pequeñas (20-50 ha) y el tramo de menor extensión (51-100 ha) de las medianas empresas se comportaron como miniempresas: el punto esencial de su utilización se centra en huertas y olivares de regadío, pero apenas tiene importancia el cereal o los olivares de secano. Las mayores de entre las medianas empresas (101-200 ha) y, principalmente, los latifundios menores (201-500 ha) ocupan grandes zonas de riego. Es de desta- 
car que los mayores ( $>1.000 \mathrm{ha}$ ) sorprenden por tener extensos campos de cereal y olivar de secano; además, llama la atención la gran porción de monte y pasto.

TABLA 3

USOS SEGÚN EL TAMAÑO DE LAS FINCAS EN LA PROVINCIA DE JAÉN 1979

\begin{tabular}{rrrrrrrr}
\hline $\begin{array}{c}\text { Clases de } \\
\text { tamaño }\end{array}$ & $\begin{array}{c}\text { Superficie } \\
\text { total }\end{array}$ & Regadío & $\begin{array}{r}\text { Cereal } \\
\text { secano }\end{array}$ & $\begin{array}{c}\text { Olivar } \\
\text { regadío }\end{array}$ & $\begin{array}{r}\text { Olivar } \\
\text { secano }\end{array}$ & $\begin{array}{r}\text { Monte y } \\
\text { pastos }\end{array}$ & Pinar \\
\hline $20-50$ & 150 & 100 & 0 & 50 & 0 & 0 & 0 \\
$51-100$ & 2284 & 963 & 106 & 1.027 & 215 & 3 & 0 \\
$101-200$ & 7.885 & 1.711 & 2495 & 1.832 & 1.599 & 201 & 30 \\
$201-500$ & 78.472 & 2.519 & 19.622 & 1.802 & 13.324 & 33.413 & 7.958 \\
$501-1.000$ & 77.557 & 713 & 9.814 & 1.460 & 5.269 & 44.222 & 16.178 \\
$>1.000<$ & 156.406 & 528 & 9.391 & 125 & 1.119 & 106.455 & 38.789 \\
Total & 322.754 & 6.534 & 41.428 & 6.296 & 21.526 & 184.294 & 62.955 \\
\hline
\end{tabular}

Fuente: «Relación» 1979.

Monte y pasto

La mayor parte de la superficie total utilizada estaba ocupada por el uso extensivo de la tierra: bien únicamente por pino, por monte ¿y pasto?, o por pinar, monte y pasto en conjunto y nada más (tabla 4).

El examen de los datos nos permite observar que estos aprovechamientos extensivos superan con creces la mitad de la tierra aprovechada, localizándose principalmente en las montañas del Alto Guadalquivir: Sierra Morena es una región preferentemente de dehesas, ocupada en parte por monte, o bien por pastizales; pero la vegetación sobre las pizarras paleozoicas es esteparia y deficiente. Sin embargo, en las escarpadas serranías de oriente y del sur existen grandes superficies de pinares. En 1979, los propietarios de grandes dehesas eran municipios, sociedades anónimas o particulares que muchas veces se habían asociado con el Instituto de Conservación de la Naturaleza (ICONA). A este pertenecía casi todo - como ocurre con el municipio de Hornos- o mucho - como en el municipio de Segura de la Sierra. La «Relación» menciona 23 veces a ICONA como propietaria, y 10 veces como socia. Así, ICONA, con la finca Canjorros en el municipio de Santisteban del Puerto, era propietaria 
TABLA 4

FINCAS CON USOS MUY EXTENSIVOS EN LA PROVINCIA DE JAÉN 1979

\begin{tabular}{lcccc}
\hline \multicolumn{1}{c}{ Uso de tierra } & $\begin{array}{c}\text { Número } \\
\text { de empresas }\end{array}$ & $\begin{array}{c}\text { Superficie } \\
\text { media por } \\
\text { empresa en ha }\end{array}$ & $\begin{array}{c}\text { Área de uso } \\
\text { de todas } \\
\text { las empresas } \\
\text { en cuestión } \\
\text { en ha }\end{array}$ & $\begin{array}{c}\text { Porcentaje (\%) } \\
\text { sobre la } \\
\text { superficie total } \\
\text { (322.754 ha) }\end{array}$ \\
\hline $\begin{array}{l}\text { Puramente pinar } \\
\text { Puramente } \\
\text { monte y pasto }\end{array}$ & 136 & 1151,27 & 51.807 & 16,05 \\
$\begin{array}{l}\text { Finca con nada } \\
\text { más que pinar, } \\
\text { monte y pasto }\end{array}$ & 65 & 947,63 & 128.878 & 39,93 \\
$\begin{array}{l}\text { Suma de pinar, } \\
\text { monte y pasto } \\
\text { en fincas } \\
\text { sin otro uso }\end{array}$ & 187 & 695,83 & 4.175 & 1,29 \\
\hline
\end{tabular}

Fuente: «Relación» 1979.

de 9.500 ha de pinar, y uno de los mayores terratenientes. Una sociedad anónima era la titular de la finca Valdelagrana de Andújar, con 4.142 ha de monte y pasto.

Con todo, las áreas de monte y pino fueron menos importantes en lo que se refiere a la obtención de madera, por lo que el objetivo de los beneficios se enfocó sobre los recursos cinegéticos: 33 veces se menciona el uso de la caza. Aparentemente, la «Relación» se refiere a menudo a la explotación cinegética en Sierra Morena en los municipios de Baños de la Encina, Carboneros, La Carolina, Guarromán y Aldeaquemada. Además, una sociedad anónima con sede en Albacete ha establecido un coto de caza mayor de muflones en Andújar sobre 805 ha de monte y pasto. En 39 casos se indica directamente el uso de la dehesa para ganadería bovina y/u ovina. Siete veces se habla de toros de lidia en las fincas de Polluelo (Andújar), La Tiesa (Vilches), y también en Los Alarcones, Majadillas, Los Monasterios, Los Pausibeles y El Manto, todas ellas situadas en el municipio de Baños de la Encina. 
La extensión del regadío

En 1980 el regadío perteneciente a los terratenientes más importantes de la provincia de Jaén es limitado.

TABLA 5

FINCAS CON TERRENOS DE REGADÍO EN LA PROVINCIA DE JAÉN 1979

\begin{tabular}{lccccc}
\hline Uso & $\begin{array}{c}\text { Número de } \\
\text { empresas }\end{array}$ & $\begin{array}{c}\text { Superficie } \\
\text { de uso de todas } \\
\text { las empresas } \\
\text { en cuestión } \\
\text { en ha }\end{array}$ & $\begin{array}{c}\text { Superficie } \\
\text { media por } \\
\text { empresa } \\
\text { en ha }\end{array}$ & $\begin{array}{c}\text { Porción } \\
\text { en la superficie } \\
\text { total de } \\
322.754 \text { ha } \\
\text { en } \%\end{array}$ & $\begin{array}{c}\text { Porción } \\
\text { en la SAU } \\
\text { de } 75.505 \text { ha } \\
\text { en \% }\end{array}$ \\
\hline $\begin{array}{l}\text { Regadío } \\
\text { Olivar de } \\
\text { regadío }\end{array}$ & 115 & 6.534 & 56,82 & 2,02 & 8,65 \\
Suma & 74 & 6.296 & 85,08 & 1,95 & 8,34 \\
\hline
\end{tabular}

Fuente: «Relación» 1979

En 1984, los regadíos sumaron en toda la provincia 66.249 ha12 (Quirós Romero, 1984, p. 166). Según «Fundación» (2001, p. 3), en los años 1990 existían 145.576 ha de regadío. La «Relación» indica 6.534 ha de campos de regadío y, separadamente, 6.296 ha de olivares de regadío. Este uso intensivo de la tierra de los latifundistas es pequeño teniendo en cuenta su escasa extensión de 12.830 ha (tabla 5). Por su parte, el regadío de los minifundios sí abarcaba notoriamente más extensión.

Campos de regadío de más de 200 ha existen principalmente en la Campiña, a lo largo del río Guadalquivir, entre los municipios de Úbeda y Marmolejo, pero también en el río Guadalén entre los municipios de Vilches y Jabalquinto. Islotes locales de riego, claramente con menos de 200 ha, se encuentran en las cuencas intramontanas de la Sierra de Segura, Peal de Becerro o Solera. Pero también los municipios de Cazorla, Quesada, Pozo Alcón y Huesa, en las sierras laterales y sureñas, contaban con áreas de riego notables. Este hecho ocurría en igual medida con los municipios de Jaén y Linares.

\footnotetext{
12 Quirós Romero (1984) no especifica el área de regadío de manera muy concreta, pero se puede estimar que en este territorio los cultivos y el arbolado de regadío se consideran en conjunto. 
En cuanto a los olivares de regadío, el área intensivamente utilizada de Baéza-Úbeda llama la atención. En el oeste existían cinturones menores con olivares de riego'13. Al fin es claro que las mayores extensiones de regadío se concentran en la mitad occidental de la provincia de Jaén. Hacia la provincia de Granada, la Campiña se desarrolla más ampliamente, es menos abrupta y se ofrecen terrazas de gran tamaño para el mejoramiento de la técnica de regadío

FIGURA 2

\section{JAÉN: SUPERFICIE TOTAL REGADA DE OLIVAR Y CEREAL DE EXPLOTACIONES MAYORES 1979}

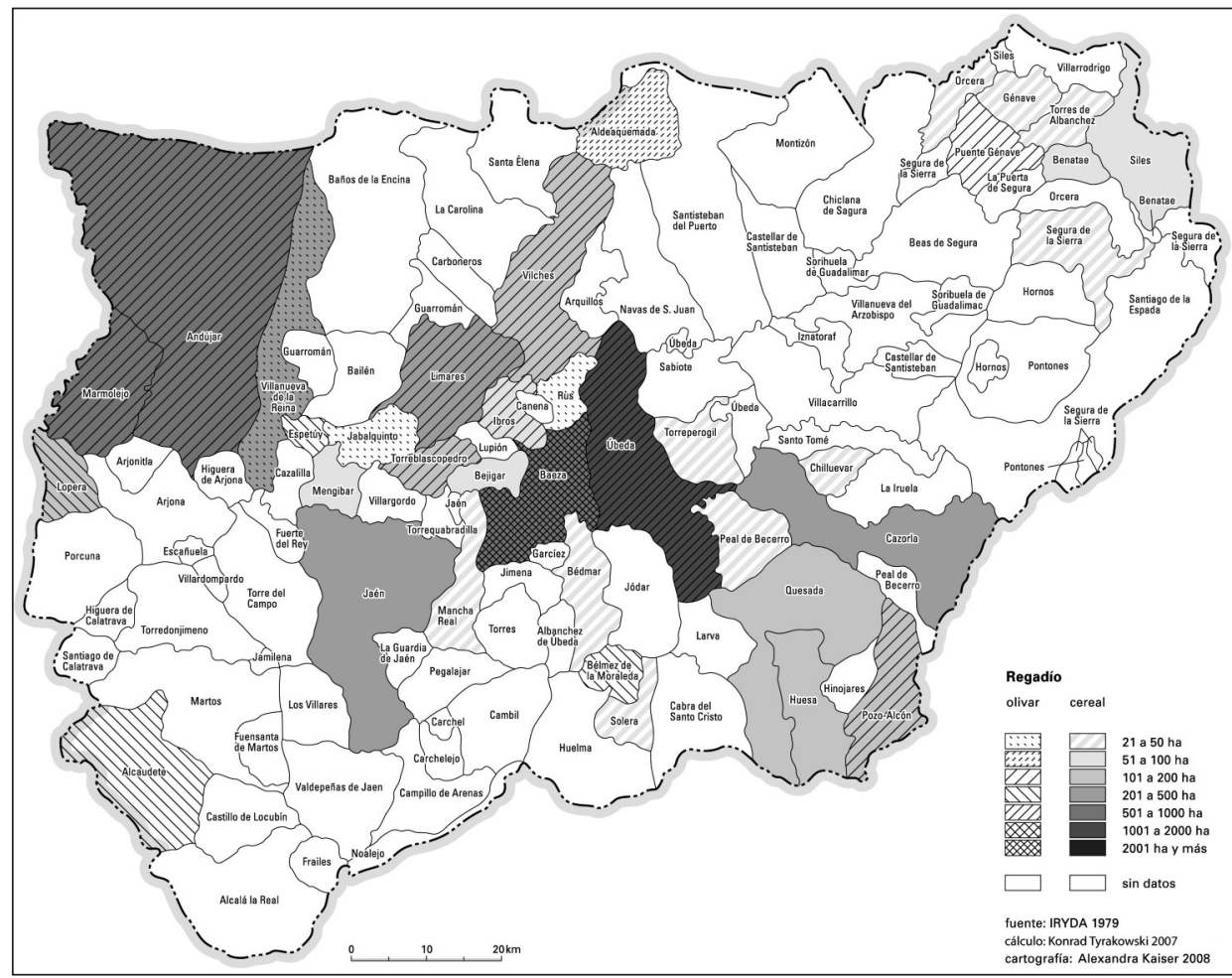

${ }^{13}$ La representación cartográfica para los grandes municipios de Sierra Morena (figura 2) simula extensiones mayores, que en realidad no existen. Las superficies efectivas se hallan en la parte meridional. 
La extensión de los campos de secano

La «Relación» de 1979 señalaba dos culturas concretas en secano. Los campos de cereales ocupaban 41.428 ha y los olivares dominaban 21.526 ha de la extensión total. Existían, por tanto, dos cultivos importantes de la «trilogía mediterránea» (trigo, olivo, vid) que reinaban en la superficie agraria de la provincia. En Jaén, el olivo había aumentado su importancia desde mediados del siglo XVIII, asegurando su predominio a partir de 1888 (Higueras Arnal, 1961, p. 103)

TABLA 6

EMPRESAS CON CAMPOS DE CEREAL Y OLIVAR DE SECANO DE JAÉN 1979

\begin{tabular}{lccccc}
\hline $\begin{array}{c}\text { Uso } \\
\text { de tierra }\end{array}$ & $\begin{array}{c}\text { Número de } \\
\text { las empresas }\end{array}$ & $\begin{array}{c}\text { SAU de todas } \\
\text { las empresas } \\
\text { en cuestión } \\
\text { en ha }\end{array}$ & $\begin{array}{c}\text { Promedio } \\
\text { de superficie } \\
\text { por empresa } \\
\text { en ha }\end{array}$ & $\begin{array}{c}\text { Prorrata } \\
\text { en la superficie } \\
\text { total de } \\
\text { 322.754 ha en \% }\end{array}$ & $\begin{array}{c}\text { Prorrata } \\
\text { de la SAU } \\
\text { de 75.505 ha } \\
\text { en \% }\end{array}$ \\
\hline Cereal & 214 & 1.428 & 193,59 & 12,83 & 54,87 \\
Olivar & 173 & 21.526 & 124,43 & 6,67 & 28,51 \\
Suma & 387 & 62.954 & & 19,50 & 83,38 \\
\hline
\end{tabular}

Fuente: «Relación» 1979.

Este hecho se explica por dos razones: la demanda creciente de aceite en el siglo XIX y el retroceso de la Hermandad de Pastores de la Mesta, que impulsaron a los latifundios cerealistas en dirección al cultivo del olivo. Además, la función social del olivo era de una gran importancia porque exigía poco trabajo y permitía de este modo al pequeño propietario una segunda ocupación (op. cit.).

Con el paso del tiempo, el olivar de secano se extendió por la provincia, principalmente por las terrazas bajas y en las lomas margosas centrales. Los olivares desplazaron a los campos de cereales y empezaron a desarrollar su papel como monocultivo (figura 4) ${ }^{14}$. Los datos para 1979 muestran que los olivares, tanto de regadío como de secano, ocupaban unas 27.822 ha del mediano o

${ }^{14}$ Los olivares alcanzaron en 1972 en la provincia de Jaén el 55,3\% del total de la superficie agrícola útil (INE 1979, p. 31), en el año 2000 llegaron a alcanzar el 85,5 \% (Fundación 2001). 


\section{FIGURA 3}

\section{JAÉN: SUPERFICIE TOTAL DE OLIVAR Y CEREAL DE SECANO DE EXPLOTACIONES MAYORES 1979}

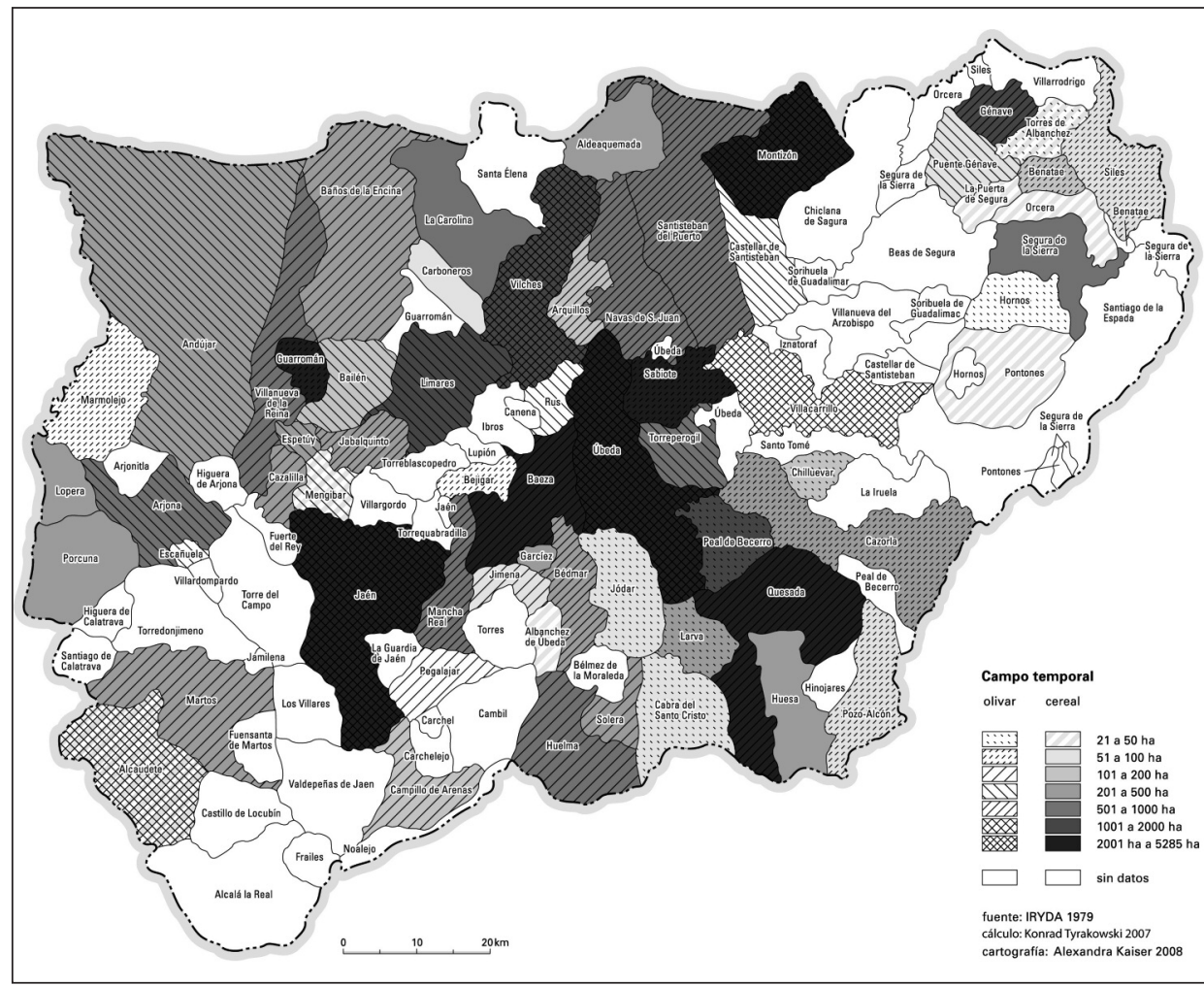

gran latifundio, equivalentes a solo el 36,85\% de la SAU. Como demuestra la tabla 6, en las grandes fincas se cultivaban sobre todo cereales; por consiguiente, el olivo fue un cultivo preferido por los pequeños propietarios.

En 1979 se esperaba en la provincia nuevamente un aumento de la superficie del olivar. En Andalucía se tenía el concepto de que el hecho de tener propiedades valía aún más que tener una cuenta de ahorro en el banco.

Como podemos observar, en 1977 existían en la provincia de Jaén alrededor de 450.000 ha dedicadas a olivares, pero la mediana y gran propiedad registró únicamente cerca de 27.800 ha de olivo, lo que es claro índice de la importancia de la pequeña propiedad en la cultura del olivo. 
TABLA 7

OLIVARES EN LA PROVINCIA DE JAÉN SEGÚN LAS MEDIANAS Y GRANDES PROPIEDADES 1979

\begin{tabular}{ccc}
\hline Clases de propiedades en ha & Olivares de regadío en ha & Olivares de secano en ha \\
\hline $21-50$ & 50 & 0 \\
$51-100$ & 1.027 & 215 \\
$101-200$ & 1.832 & 1.599 \\
$201-500$ & 1.802 & 13.324 \\
$501-1000$ & 1.460 & 5.269 \\
$>1000$ & 125 & 1.119 \\
Sumas & 6.296 & 21.526 \\
\hline
\end{tabular}

Fuente: «Relación» 1979.

FIGURA 4

DESARROLLO DEL TERRENO DE OLIVAR EN LA PROVINCIA DE JAÉN 1888-2000

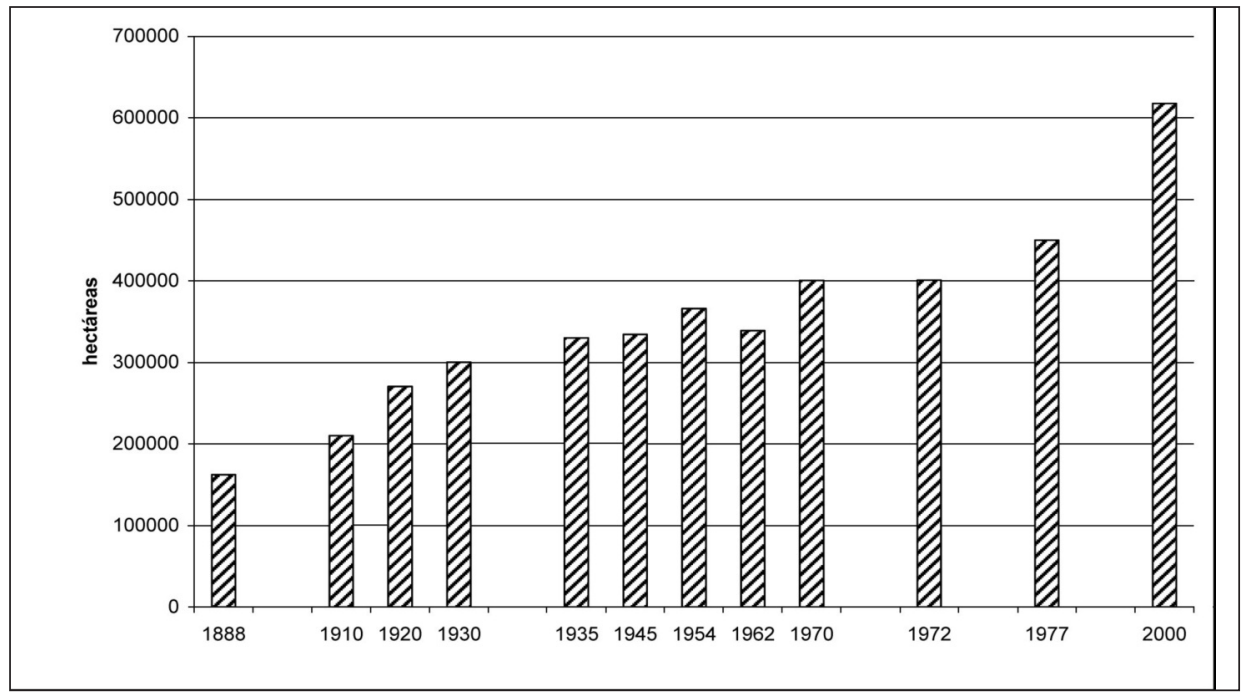

Fuente: K. Tyrakowski, 1987; Fundación 2001; diseño: K. Tyrakowski F. 2007.

Estudios Geográficos, Vol. LXXII, 270, pp. 231-262, enero-junio 2011

ISSN: 0014-1496, eISSN: 1988-8546, doi: 10.3989/estgeogr.201110 
TABLA 8

EJEMPLOS DE PROPIEDAD MUNICIPAL EN LA PROVINCIA DE JAÉN 1979

\begin{tabular}{|c|c|c|c|c|c|c|}
\hline $\begin{array}{l}\text { Nombre } \\
\text { de la finca }\end{array}$ & $\begin{array}{c}\text { Superficie } \\
\text { en ha }\end{array}$ & $\begin{array}{c}\text { Cereal } \\
\text { de secano } \\
\text { en ha }\end{array}$ & $\begin{array}{l}\text { Monte } \\
\text { y pasto } \\
\text { en ha }\end{array}$ & $\begin{array}{l}\text { Pinar } \\
\text { en ha }\end{array}$ & Propietario & Domicilio \\
\hline Dehesa Bajal & 9.194 & 3.826 & 5.368 & & Ayuntamiento & Guarromán \\
\hline El Baldío & 736 & & 736 & & Ayuntamiento & Marmolejo \\
\hline $\begin{array}{l}\text { Dehesa de } \\
\text { Quesada }\end{array}$ & 7.738 & 2.000 & 3.738 & 2.000 & Ayuntamiento & Quesada \\
\hline La Carnicera & 1.150 & & 1.150 & & Ayuntamiento & $\begin{array}{l}\text { Santisteban } \\
\text { del Puerto }\end{array}$ \\
\hline $\begin{array}{l}\text { Barranco } \\
\text { Barrero }\end{array}$ & 914 & & 914 & & Ayuntamiento & Vilches \\
\hline
\end{tabular}

Fuente: «Relación» 1979.

\section{Situación social y procedencia regional de los propietarios}

Los propietarios de las 507 empresas eran fundamentalmente particulares. Un total de 393 empresarios (el 77,51 \% de todas las fincas analizadas) trabajaban sus propiedades según principios de economía privada. Junto a ellos existían colectivos que administraban latifundios, 11 de los cuales eran propiedad de municipios, al tiempo que 5 grupos de campesinos trabajaban colectivamente en 5 cortijos.

Por otra parte, 43 sociedades anónimas invirtieron en la agricultura. Otras instituciones que también menciona la «Relación» son: un colegio, al cual pertenecían 2 fincas, y 3 bancos, los cuales se establecieron como propietarios de dichos terrenos.

En la provincia de Jaén, según la estructura social existían los siguientes tipos de propietarios:

- La nobleza como terrateniente, que tal vez todavía podría tener terrenos del tiempo de la reconquista o de las amortizaciones del siglo XIx. Pero hemos de decir que este estrato social no tuvo mucha repercusión en la provincia. Entre los particulares en 1979 solo cinco eran nobles: entre ellos se encontraban el duque de Peñaranda, la duquesa de Cárdenas, el marqués del Mérito, el marqués de Viana y el conde de Santa Ana.

- 32 municipios eran dueños de grandes extensiones de monte, pastos y campos. La superficie en posesión de dichos municipios iba desde las 
284 ha de pastos en el municipio de Puente Génave o las 340 ha de pinar en Bailén, hasta las 7.738 ha de cereal de secano, pasto y pinar en Quesada o las 9.194 ha de cereal de secano y pastos en el municipio de Guarromán. Es de destacar que estos municipios, a pesar de estar situados en las zonas más céntricas de la comarca y aun poseyendo una gran riqueza natural, no fueron afectados por las desamortizaciones. La procedencia de estas propiedades queda aún por investigar, ya que las parcelas de estas extensiones estaban arrendadas.

- La existencia de grupos de campesinos que en común trabajaban una finca remite a restos de una «reforma agraria desde abajo» como la que ocurrió durante la II República (1931-1936), y como fue el caso de Garcíez, donde en los años 1970 la marquesa de Viana vendió 375 ha olivar de su propiedad a un comerciante de joyas. En 1981, las 100 familias de campesinos provenientes de esta tierra lucharon con todas sus fuerzas con cada revendedor hasta que casi un centenar de estos campesinos pudo comprar estos olivares a partes iguales («Relación, 1979»; El País 22.3.1998).

- 42 sociedades anónimas y otras 3 sociedades mercantiles que aparecen como empresas agrarias, en las que se puede observar cómo las nuevas formas de organización se extienden entre las fincas. La formación de éstas es típica en empresas de cultivo de cereal de secano no intensivo, aunque también existen casos que quieren aprovechar los beneficios fiscales como base para una intensificación a partir del regadío (Mata Olmo, 1987, II, p. 219). La «Relación» de 1979 enumera 22 sociedades anónimas que utilizan exclusivamente terrenos extensivos de monte o pasto, con extensiones que van desde las 7.158 ha en el municipio de Baños de la Encina a las 400 ha en el de Santisteban del Puerto. Hay que añadir a este tipo de organización también 14 empresas que aprovechan en su mayoría tierras extensivas (pasto, olivar de secano, cereal de secano). Menos frecuente es el caso de la economía de regadío intensivo: únicamente 5 empresas de mediano tamaño (de 87 a 300 ha) han sido anotadas como sociedades anónimas aunque en dos casos no se ha podido especificar cuáles eran.

- El Instituto de la Sagrada Familia en Andújar, el cual era propietario de 2 fincas arrendadas.

- Y un banco en Madrid, otro en Granada y otro en Úbeda, que tuvieron cada uno una finca jiennense en propiedad.

La «Relación» menciona 507 empresas que se han agrupado en la tabla 9. 
TABLA 9

ORGANIZACIÓN DE LA DIRECCIÓN DE 507 FINCAS EN LA PROVINCIA DE JAÉN 1979

\begin{tabular}{lrcl}
\hline $\begin{array}{l}\text { Tipo de } \\
\text { administración }\end{array}$ & Número & $\begin{array}{c}\text { Prorrata de todas } \\
\text { las empresas en \% }\end{array}$ & Especialidades \\
\hline Municipio & 32 & 6,31 & $\begin{array}{l}\text { 7 municipios formaron un consorcio } \\
\text { con ICONA }\end{array}$ \\
ICONA & 23 & 4,54 & \\
Banco & 3 & 0,59 & 3 empresas \\
Sociedad anónima & 45 & 8,87 & \\
o empresa & 2 & 0,39 & 20 particulares con administrador \\
Colegio & 5 & 0,99 & \\
Grupo de campesinos & 397 & 78,30 & \\
Particular & 507 & 100,00 & \\
Total & & & \\
\hline
\end{tabular}

Fuente: «Relación» 1979.

Un interés especial tienen los 397 empresarios particulares que, según opinión tradicional, son «absentistas», porque en su gran mayoría no vivían en el campo y por tal motivo no se ocupaban directamente de su labor. Únicamente 31 de los empresarios vivían en 1979 en su cortijo y tuvieron de este modo contacto directo con su empresa. Esto significó que del total de los empresarios, únicamente un 7,81\% tuvo influencia inmediata en la dirección de sus tierras. Los latifundistas estuvieron representados por un administrador impuesto. Pero la mayoría de los propietarios vivían muy lejos de sus fincas. Entre los dueños particulares, destacaban las familias burguesas y urbanas como los Muñoz-Cobos, Miñón, Jiménez, Flores de Quiñones y Romero Granados ${ }^{15}$.

En total, la «Relación» enumera 80 asentamientos, entre urbanos y rurales, donde radican los domicilios de los empresarios, de los cuales 21 de ellos $(26,25 \%)$ se situaron fuera de la provincia (figura 5). Entre estas poblaciones sobresalen Córdoba con 15 menciones, Granada con 31 y Madrid con 61. Dentro de la provincia de Jaén aparecía en primer lugar la ciudad de Jaén con 33 menciones, seguida por Linares con 28, Úbeda con 23 y Baeza con 1416. La

\footnotetext{
15 A algunos de ellos hace referencia Mata Olmo (1982, pp. 143-144).

16 Mata Olmo (1987, II, pp. 250-252) cartografió las áreas de residencia de una parte de los oligarcas agrarios en los ensanches alrededor del núcleo del casco antiguo en Madrid, Córdoba 
gran propiedad agraria en la provincia habita entorno a la zona central, en la capital y en otros importantes núcleos rurales. Pero también en la periferia existían centros más pequeños, con grandes propietarios de tierras, como por ejemplo Arjona, Andújar, La Carolina, Villanueva del Arzobispo, Villacarrillo, Orcera, Segura de la Sierra y Santiago de la Espada. Por contra, pocas concentraciones rurales de grandes propietarios se encontraban en la periferia del sur de la provincia.

Ese reparto regional hace suponer que:

- Existía un absentismo absoluto, en el cual el dueño vivía muy lejos de su propiedad y, residiendo en Madrid, Córdoba o Granada, en pocos o casi ningún caso conocería la realidad de la administración de su empresa (podría parecer posible que esa ausencia causara un aprovechamiento deficiente de las fincas).

- Existía un absentismo relativo, en los casos en que los propietarios vivían fuera de sus fincas, pero dentro de la provincia de Jaén. Esa cercanía a la empresa permite suponer que los dueños, con mayor o menor asiduidad, podían supervisar sus fincas.

- Se podría esperar un laboreo más intensivo en los 20 predios dirigidos por administradores, que personalmente supervisaban la organización laboral así como la realización del proceso del cultivo y controlaban exactamente los gastos y ganancias de su jefe. Estaban considerados como los brazos del propietario.

- El grupo de aquellos dueños, que según la «Relación» vivían en su cortijo y personalmente dirigía su explotación era pequeño. En tan solo 31 casos de las citadas 397 empresas $(=7,81 \%)$, sus dueños residían en la misma propiedad. Se puede creer que esa situación implicaba un uso más provechoso de las tierras.

Esa diferenciación según la ausencia o la presencia de los propietarios hace esperar que las empresas mostraran una diversidad extraordinariamente amplia en lo que se refiere a la intensidad del aprovechamiento agrario. Esta es la cuestión de la que aquí se trata.

\footnotetext{
y Jaén. En Jaén, las zonas preferidas para vivir fueron el Paseo de la Estación (antes Avda. del Generalísimo) y la Avda. de Madrid. Un croquis interesante muestra las moradas actuales de grandes terratenientes de Andalucía, Castilla-La Mancha, Cataluña y Aragón en Madrid a lo largo del Paseo de la Castellana y cerca de la Calle de Alcalá (documentación aportada por El País del 21.10.2007).
} 


\section{FIGURA 5}

DISTRIBUCIÓN DE LOS DOMICILIOS DE LOS EMPRESARIOS DENTRO Y FUERA DE LA PROVINCIA DE JAÉN 1979

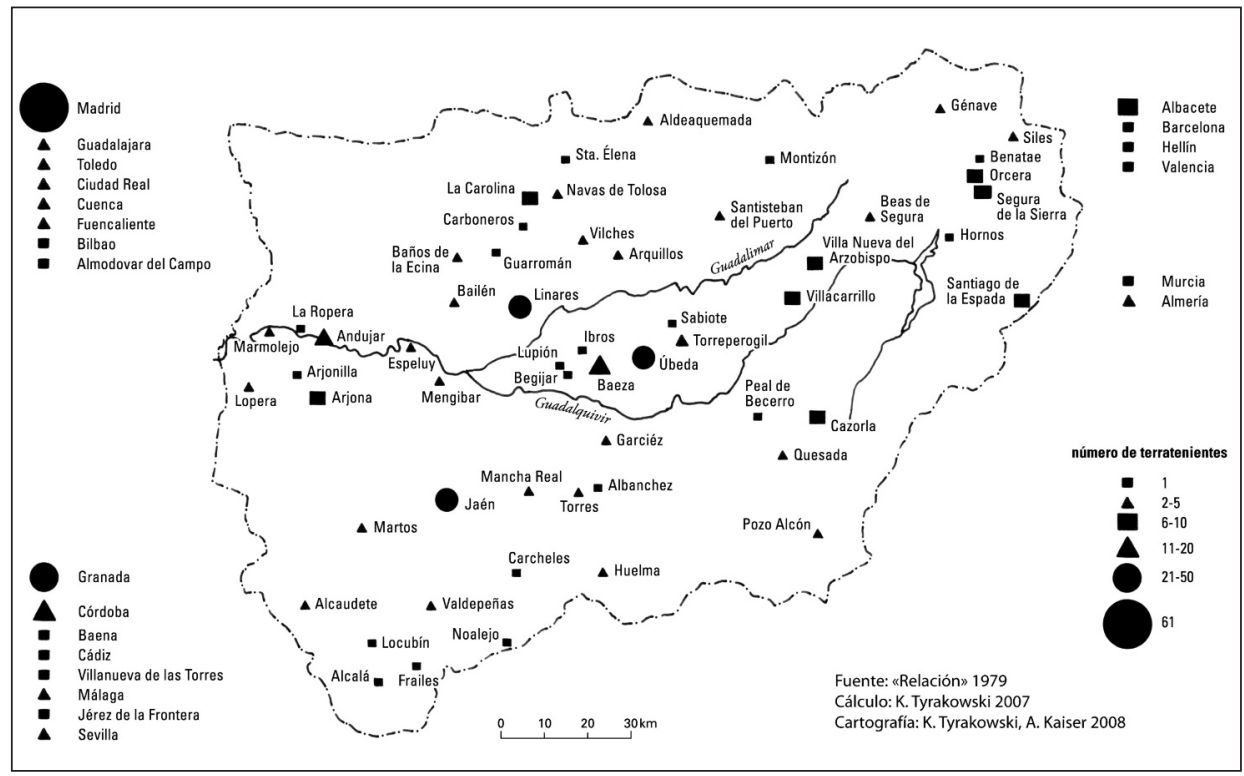

La «Relación» de 1979 indica claramente el grado de aprovechamiento. Bajo el epígrafe «Observaciones» se verifican calidades de la administración empresarial, entre las que es de destacar:

- La administración directa de 402 fincas, lo que supone un 79,29\% de las 507 propiedades investigadas. Si de estas 402 se deducen las 67 propiedades en manos de entidades (SS. AA., empresas, instituto, municipios, bancos) pero también administradas directamente, quedan aún 345 explotaciones privadas directamente gestionadas, lo que supone el $85,82 \%$ de los propietarios que no son entidades. Es decir, los propietarios privados que vivían lejos ejercían una influencia directa en el laboreo de sus empresas. Esto entra en clara contradicción con la opinión de que los propietarios absentistas no realizaban una correcta administración de sus fincas, lo que tendría una repercusión desventajosa en el aprovechamiento de sus tierras. Pero ya Martínez Alier (1968, pp. 321-332) había declarado que en este aspecto los terratenientes, tanto del campo como de la ciudad, trabajaban generalmente sus tierras de una manera más eficaz. 
- Este laboreo directo y por ello también intensivo durante los años 1970 era un fenómeno bastante moderno que fue iniciado por una mejoría de la infraestructura (Mata Olmo, 1981, p. 149) con lo que el acceso al mercado mejoró marcadamente. Por ello, disminuyo bastante el sistema de arrendamiento.

- Únicamente 89 fincas estaban, totalmente o en parte, arrendadas, de las cuales junto al arrendamiento más generalizado por dinero también existía el arrendamiento en aparcería en el que se pagaba el arrendamiento en especie.

- Ese laboreo directo presentaba resultados más eficaces: en 348 predios se constató una explotación provechosa, presentándose en las anotaciones cómo «bien, correcto, conforme». Hemos de decir, que no se ha tenido una calificación más concreta.

- Frente a todas las expectativas provocadas por la ausencia de los propietarios, se documentó únicamente en 10 fincas (Pedro Marín, en el municipio de Bedmar-Garcíez; Los Bierrales, Rincón Blanco, Sierrezuela y Dehesa, en el de Jódar; Los Palancares y Olivilla, en el de Larva; Navalcaballo, en el de Montizón; La Carnicera, en el de Navas de San Juan; La Cima, en el de Pegalajar) un aprovechamiento insuficiente. Hemos de destacar que salvo los breves comentarios «deficiente, sin explotar, bajo rendimiento» no se han podido sacar de la «Relación» argumentaciones más concretas. Ocho predios de estas 10 fincas se trabajaron de forma particular, y de las dos restantes un banco administró 1 finca, y una Asociación Anónima trabajó otra.

Interesantes son sin embargo aquellas parcelas que, según Mata Olmo (1981, p. 150), siempre fueron cerealistas; porque hubiera sido un atrevimiento por parte de los arrendatarios, con sus arrendamientos cortos (3-6 años), el haber cultivado olivos. La «Relación» documenta para 1979 que entre las 69 fincas arrendadas existían 27 unidades con tipos de cultivos mixtos, es decir, no eran exclusivamente tierras de pasto o de pino, con lo que estuvieron en arrendamiento total o parcial.

En la tabla 10 podemos observar lo siguiente:

- En contra de las observaciones de Mata Olmo (1981, p. 150), la mayor superficie arrendada no se refiere al campo de cereal sino a los pastos poco intensivos. Este hecho está relacionado con los niveles divergentes de las investigaciones: Mata Olmo analiza únicamente la Campiña de Jaén, mientras que la «Relación» considera toda la provincia e incluye los grandes pastizales de la periferia serrana. 
TABLA 10

ESTRUCTURA AGRARIA DE 27 FINCAS ARRENDADAS EN LA PROVINCIA DE JAÉN 1979

\begin{tabular}{ccccccc}
\hline $\begin{array}{c}\text { Superfície } \\
\text { total (ha) }\end{array}$ & $\begin{array}{c}\text { Campo de } \\
\text { regadío (ha) }\end{array}$ & $\begin{array}{c}\text { Campo de } \\
\text { labor de } \\
\text { regadío (ha) }\end{array}$ & $\begin{array}{c}\text { Olivar de } \\
\text { regadío (ha) }\end{array}$ & $\begin{array}{c}\text { Olivar de } \\
\text { secano (ha) }\end{array}$ & $\begin{array}{c}\text { Monte y } \\
\text { pasto (ha) }\end{array}$ & $\begin{array}{c}\text { Pinar } \\
\text { (ha) }\end{array}$ \\
\hline 26.330 & 288 & 7.851 & 105 & 2.241 & 12.881 & 2.964 \\
\hline
\end{tabular}

Fuente: «Relación» 1979

- Sin embargo, de acuerdo con la mención de Mata Olmo (op. cit.) se confirma que en los terrenos agrícolas, la tierra de cereal representa la mayor parte de los arrendamientos. Es así que podemos decir, que en promedio, casi 290 ha de la tierra eran arrendadas por una empresa.

- Llama la atención que una superficie respetable de olivares de regadío era arrendada, es decir, en termino medio, se trataba de 83 ha por finca.

- En cuanto a lo que se refiere a tierras de regadío, podemos establecer que tratándose de huertas o de olivares, en ambos casos se arrendaron únicamente pequeñas parcelas. Sin duda, el total de la huertas de las 507 fincas descritas era limitado, 6.534 ha (tabla 3). En cuatro casos se acordó que el contrato de arrendamiento pasaría a estar considerado como aparcería, es decir como pago en especie. De esta forma, este derecho tradicional estaría vigente en 1979 tan solo en dimensiones reducidas.

- En cuanto al número de parcelas de las empresa, Mata Olmo (1981, p. 157) argumenta que el grado de la parcelación-disgregación entre los pequeños agricultores era significantemente mayor que entre los latifundistas. Para aclarar ese problema partimos de tan solo conocimientos aproximados que la «Relación» nos aporta comparando los apellidos de los empresarios en diferentes municipios. La existencia del mismo apellido o partes de estos permite la conclusión de que el/la dueño/a tuvieron propiedades en varios municipios y, de esta forma, se podían asignar varias fincas a un/a propietario/a de forma que esta familia formaba parte de la oligarquía rural o de la «burguesía titulada» gracias a sus grandes propiedades (op. cit., p. 143). 


\section{ASPECTOS SOCIO-ECONÓMICOS Y CONCLUSIONES}

El vacío político que siguió a la muerte de Franco, en 1975, introdujo a la población y a la economía en movimientos de una gran trascendencia. Por un lado se presentaron nuevas posibilidades positivas de desarrollo. Por el otro, se esperaba un recrudecimiento de las luchas de clases. Este hecho se manifiesta por ejemplo en un análisis de las situaciones agro-sociales que publicó una revista:

Por último están los grandes agricultores. Estos dominan la burocracia de la Hermandad Nacional. En el paseo del Prado hablan con acento andaluz hasta las secretarias de la Hermandad Nacional. La clave de esta clase social de grandes agricultores es que muchos tienen otras profesiones (médicos, abogados, ingenieros, etc.) y otras fuentes de ingresos (acciones, casas en la ciudad, negocios urbanos farmacias, tiendas, garajes, etc.-). [...] Son cultivadores directos, pero no personales, y aunque obtengan menos precios superviven por la revalorización de sus tierras. [...] En los próximos años, las contradicciones entre clases seguirán desarrollándose [...] también aquellas que encuentran su origen en la irracionalidad del capitalismo y en su autodestrucción del sistema por degradación y agotamiento de los recursos. (Triunfo, 18.12.1976, p. 45)

En la «Relación» se documenta cómo predios medianos y grandes de la provincia de Jaén demuestran un absentismo de los propietarios y la administración directa, pero no personal, con el resultado predominante de un uso de los predios en cuestión. Esa evaluación positiva estaba relacionada con la sustitución de fuerza humana por el empleo de la técnica. En mayor grado se sustituyeron al principio los tractores nacionales por tractores importados. En 1973, en el municipio de Jaén, se adquiría por primera vez una cosechadora de algodón. En 1982, existían 55 unidades en cooperativas y dos en empresas privadas. Los efectos de esa onda técnica que ya había empezado en los años 60 se establecieron principalmente dentro de las empresas medianas, devas tando el mercado laboral. Los puestos tradicionales de trabajo en los cortijos (pastores, jornaleros, yunteros) se suprimieron, los animales de tiro ya no se mantenían. Únicamente la cosecha de la aceituna quedó como trabajo manual, ya que era difícilmente mecanizable debido a las pendientes y a un arbolado poco uniforme.

Pero el paro llegó a ser una obsesión y la diferencia de intereses entre terratenientes y jornaleros salió abiertamente a la luz: peones andaluces combatieron contra la utilización de máquinas (El País 13.11.1983), muchos desocupados no encontraron siquiera los 10 días de trabajo al año para tener su derecho al subsidio de paro (El País 20.12.1985). En 1980, se contabilizaron 


\section{Foto 1}

\section{OLIVARES EN LAS LOMAS MARGOSAS AL NORTE DEL CERRO DE LA ARTESILLA CERCA DE PEGALAJAR (JAÉN)}

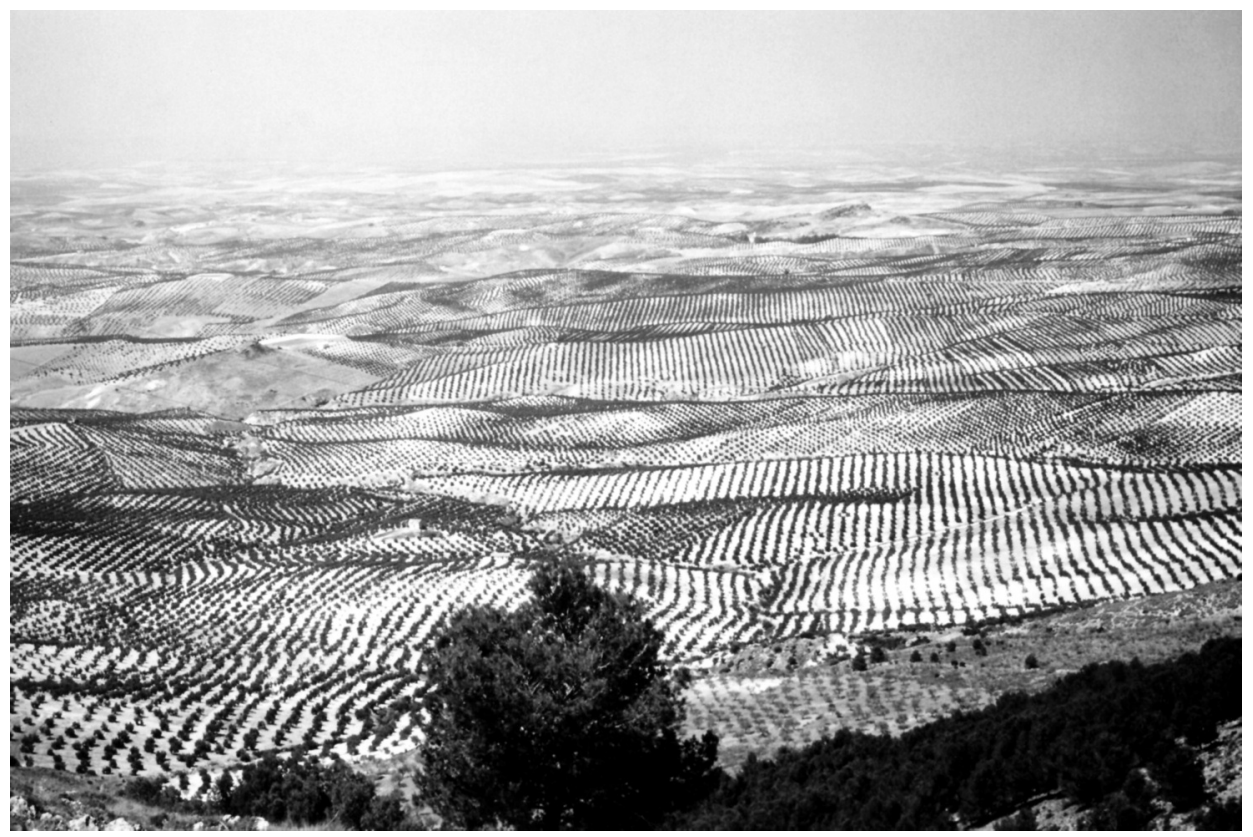

Foto: K. Tyrakowski F. 1991

400.000 andaluces en paro, lo que representaba el 17\% de la población activa (Süddeutsche Zeitung 22.7.1980). Pero el cambio socioeconómico, conocido ya en otros países europeos operaba también en Andalucía: los dueños de predios mayores se transformaron en empresarios agrarios interesados en la producción y el beneficio, la población rural emigraba y buscaba nuevos puestos de trabajo en los servicios, en el turismo, en las ciudades, en la industria ${ }^{17}$.

17 Un buen ejemplo de este cambio estructural de uso agrario se ve muy bien en los exhuertos de la colonia Miraelrío del INC/IRYDA, situada entre los ríos Guadalén y Guadalimar. Sus 287 ha para los huertos de regadío llegaron de la hacienda Miraelrío por expropiación en 1963. En 1982 sólo las faldas del cerro donde se sitúa el pueblo estuvieron ocupadas por olivares; las parcelas al pie de la pendiente estuvieron utilizadas en su mayoría por algodón (Tyrakowski, 1993, p. 107). Hoy en día están totalmente aprovechadas por olivares, el pueblo está casi vacío porque la mayoría de los ex-colonos se buscó trabajo en otros sitios. 
Digresión: Esa nueva línea de empresas puede estar representada por el cortijo «La Torre de Gil de Olid» en el municipio de Baeza (foto 2). Situado sobre una alta terraza fluvial del Guadalquivir, se trataba originalmente de una casa-torre, como todavía hoy en día se puede ver en la fuertemente arruinada en Torrequebradilla. Por cierto, ese lugar ya era utilizado por un poblado romano, habiéndose encontrado en una de sus parcelas monedas y vasijas lo que dio lugar a que 135 ha fueron declaradas zona arqueológica. Una gran importancia histórica alcanzó este sitio, cuando 33 caballeros distinguidos en la reconquista de Baeza recibieron propiedades de manos del rey Fernando III (m. 1252) y del Rey Alfonso X (m. 1284); es decir, que ese cortijo-torre ya pudiera haber existido en el siglo XIII (MuñozCobo Muñoz-Cobo, 1957). Un muro muy fuerte en el que está integrada la torre rodea el cortijo que en 1845 fue reconstruido de nuevo. En este lugar existía antes una almazara. Además hay un gran establo que hoy es cochera, algunos cobertizos para los utensilios agrícolas y una capilla en la cual están enterrados muchos de los anteriores dueños y, en tiempos pasados, se celebraba la santa misa en los domingos y días festivos. La propietaria, de edad avanzada, vivía en el año $2006^{18}$ en Granada; su esposo, muerto, había sido fiscal militar. El cortijo estaba habitado por un guarda con su familia mientras el administrador vivía en Úbeda. Fuera del casco antiguo hay una almazara y un pozo y sobre la colina una campestre pista de aterrizaje; en 2006, una avioneta fue arrendada para fertilizar y controlar las plagas. En 1979 tenía la propiedad, con 743 ha, una extensión considerable (tabla 11), que en 2006 todavía sumaban cerca de 400 ha de cereales y olivares, principales cultivos. En 1962 se habían vendido 70 ha al Estado que entonces había fundado la colonia «Puente del Obispo» con 110 jornaleros agrícolas con parcelas complementarias dentro del marco del «Plan Jaén» (Tyrakowski 1987, pp. 126, 143). Junto al guarda, en 2006 trabajaron tres jornaleros fijos y otros tres contratados temporalmente. Por el hecho de que las precipitaciones anuales alcanzaban solo $300 \mathrm{~mm}$, se cultivaron cerca de 13.000 olivos de unos 60-70 años con riego por goteo. Así se pudieron aumentar las cosechas en un $25 \%$ aproximadamente.

La provincia de Jaén perdió población de manera continua desde la guerra civil de 1936-1939 (Nadal, 1988, p. 232). En verdad, poco antes de la entrada de España en la CE se solicito explícitamente una reforma agraria andaluza (El País 2.11.1983, 4.11.1983, 31.1.1999). Pero más raramente se demandó un repartimiento de tierra: «La tierra para quién la trabaja» (El País 20.4.1994, 22.3.1998, 3.7.2002), cambiado frecuentemente por «La tierra para trabajarla» (Cambio 16 7.11.1083, 25.2.1985). Muy raras veces se amenazaba con la ocupación de una finca como en Jódar (Diario Jaén 26.8.2006). Y

18 Según informaciones durante una excursión con estudiantes de geografía de la Universidad de Eichstaett-Ingolstadt, realizada en el año 2006. 


\section{TABLA 11}

ESTRUCTURA DEL CORTIJO GIL DE OLID (MUN. BAEZA) 1979 (EN HA)

\begin{tabular}{cccccccc}
\hline Superficie & Regadío & $\begin{array}{c}\text { Cereal } \\
\text { secano }\end{array}$ & $\begin{array}{c}\text { Olivar } \\
\text { de regadío }\end{array}$ & $\begin{array}{c}\text { Olivar } \\
\text { secano }\end{array}$ & $\begin{array}{c}\text { Monte } \\
\text { y pastos }\end{array}$ & Propietario Observaciones \\
\hline 743 & 70 & 416 & 49 & 138 & 70 & S.A. & Directo, bien \\
\hline
\end{tabular}

Fuente: «Relación» 1979.

Foto 2

FRENTE DEL CORTIJO DE «LA TORRE DE GIL DE OLID»

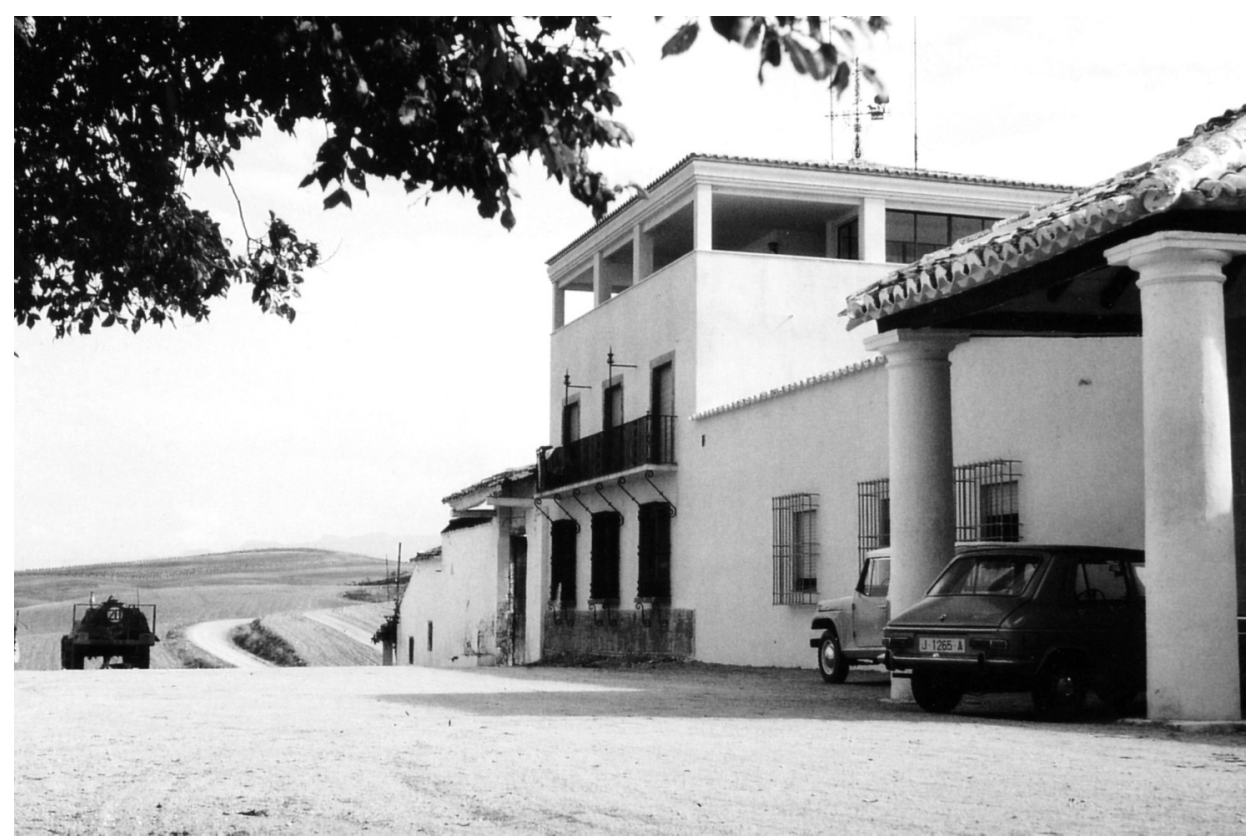

Foto: K. Tyrakowski F. 1973. 
así, los puntos de crítica arriba mencionados para la gran propiedad en la provincia de Jaén se pudieron contestar como sigue:

- En 1979 existía un dispar repartimiento de la tierra. En la provincia de Jaén, fue típica una bipolaridad entre pequeña propiedad y gran predio, que en la época de Franco había llevado hacia una fuerte disparidad social.

- Pese al absentismo, y de acuerdo con los criterios de los peritos estatales, no se podía hablar de desinterés de los latifundistas por sus propiedades. Sólo en casos excepcionales se podía detectar una economía poco rentable. En su mayoría se trabajaban bien y los latifundios eran productivos para el mercado.

- No se pudo comprobar directamente una acumulación de tierra como inversión de capital por parte de círculos de la gran burguesía, pero tampoco cabe excluirla observando los apellidos de los propietarios. No obstante, vale y ha valido hasta hoy que en Andalucía la propiedad de tierras haya sido un símbolo general de estatus social, seguro de vida y ganancia de dinero.

- No se pudo constatar dentro de la provincia de Jaén la formación de una oligarquía nobiliaria de propietarios potente.

- La dominación del mercado de trabajo debido a las nuevas tecnologías y, con ella, la depauperización de los jornaleros sí se pudo constatar en los años anteriores a 1979. Por consiguiente, los peones tuvieron que buscar otras alternativas. En la periferia, sin embargo, subsistieron bolsas de pobreza con jornaleros sin tierra.

- Los efectos del «Plan Jaén» con el que se había intentado mejorar la situación socioeconómica de la población sin tierra y sin trabajo, forzando a los terratenientes a vender parte de su patrimonio al estado, causaron solo resultados a corto plazo. En los años 80 del siglo pasado muchos colonos dejaron sus parcelas, las arrendaron, las vendieron o plantaron en los huertos antiguos olivos, como lo hicieron sus antepasados en siglos anteriores, aumentando así las parcelas del minifundio.

Ya en 1979 se pudo observar que en la Andalucía moderna y el Jaén actual existen grupos de empresarios agrarios orientados a crear ganancia y que la población agraria, antes dependiente de las grandes fincas, se está ahora orientando hacia formas de vida urbanas (El País 2.1.2001) y debía aceptar cambios difíciles, emigrar y buscar otros puestos de trabajo.

Recibido : 09/06/2008

Aceptado: 08/10/2008 


\section{BIBLIOGRAFÍA}

Araque Jiménez, E. (1983): La politica de colonización en la provincia de Jaén: análisis de sus resultados. Jaén.

Araque Jiménez, E. (1991): "La estructura de las explotaciones agrarias en la provincia de Jaén (1962-1982)". Jaén. Boletín de la Cámara oficial de Comercio e Industria de la Provincia, 689, pp. 23-31.

Artillo González, J. (1982): “Jaén, siglos XIX y XX”, Historia de Jaén. Jaén, pp. 399-532.

Artola, M., Bernal, A. M. y Contreras, J. (1978): El latifundio. Propiedad y explotación, ss. XVIII-XX. Madrid.

Carrión Carrión, P. (1975): Los latifundios de España. Barcelona, 2. a ed.

Cobo Romero, F. y Ortega López, T. M. (2005): "El partido comunista de España y la cuestión agraria en Andalucía durante el tardofranquismo y la transición política a la democracia, 1956-1983". Historia Actual Online, 7, pp. 27-42.

García de Cortázar, F. y González Vesga, J. M. (1994): Breve historia de España. Madrid.

García Torrente, R. (2005): "El sector agrario", J. Molina Herrera (dir.), La economía de la provincia de Almería. Almería, pp. 153-208.

Gómez Jover, F. (1974): "Latifundio y reforma agraria". Revista de economía política, 68 , pp. 223-233.

Guarnido Olmedo, V. (1976a): "El olivar en Andalucía Oriental. Su problemática y su cultivo sin labranza". Jaén. Boletín de la cámara oficial de comercio e industria de la Provincia, 28, pp. 17-34.

Guarnido Olmedo, V. et al. (1976b): Estudio geoeconómico de la provincia de Jaén. Jaén. Higueras Arnal, A. (1961): El Alto Guadalquivir. Estudio geográfico. Zaragoza.

Instituto Nacional de Estadística (España) (1979): Reseña estadística provincial. Jaén. Madrid.

Malefakis, E. (1972): Reforma agraria y revolución campesina en la España del siglo XX. Barcelona, 2. ${ }^{\mathrm{a}} \mathrm{ed}$.

Martínez Alier, J. (1968): La estabilidad del latifundismo: análisis de la interdependencia entre relaciones de producción y conciencia social en la agricultura latifundista de la Campiña de Córdoba. Ruedo Ibérico [s.l.].

Mata Olmo, R. (1981): "Notas sobre la situación actual de la gran propiedad en la Campiña giennense”. Estudios geográficos, XLII/163, pp. 139-165.

Mata Olmo, R. (1987): Pequeña y gran propiedad agraria en la depresión del Guadalquivir, 2 vols. Madrid.

Maurice, J. (1975): La reforma agraria en España en el siglo Xx (1900-1936). Madrid.

Muñoz-Cobo Muñoz-Cobo, D. (1957): "Heredamientos en la Torre de Gil de Olid". Boletín del Instituto de Estudios Giennenses, 12, pp. 87-124.

Nadal, J. (1988): La población española (siglos XVI a XX). Barcelona, 3. ${ }^{a} \mathrm{ed}$.

Quirós Romero, G. (1984): Economía y desarrollo desigual de la provincia de Jaén. Jaén. 
Rodríguez Molina, J. (1974-1975): "Las órdenes militares de Calatrava y Santiago en el Alto Guadalquivir (siglos XIII-XV)". Cuadernos de estudios medievales, 2-3, pp. 59-83. Sánchez Salazar, F. (1984): "El olivo y su expansión en el reino de Jaén durante el siglo XVIII". Boletín de la Real Sociedad Geográfica, CXX, pp. 133-148.

Sevilla-Guzmán, E. (1979): La evolución del campesinado en España. Barcelona.

Tamames, R. y Rueda A. (2000): Estructura económica de España. Madrid, 24. ${ }^{\text {e ed. }}$

Tyrakowski, K. (1987): Agrarkolonisation und Regionalentwicklung am oberen Guadalquivir / Spanien, unter Berücksichtigung der agrarsozialen Wandlungen im Rahmen des „Plan Jaén“ (1953-1980). Naila.

Tyrakowski Findeiss, K. (1993): "La herencia del "Plan Jaén". Los resultados de la reestructuración agraria en la periferia del Alto Guadalquivir entre 1950 y 1980". Revista de la Facultad de Humanidades de Jaén, II/2, pp. 87-114.

Tyrakowski Findeiss, K. (1995): "Los Herederos del "Plan Jaén". Los pueblos franquistas del Alto Guadalquivir al concluir su etapa de colonización en los años 80", Actas del VI Congreso Histórico sobre Nuevas Poblaciones. La Carlota et al., pp. 121-141.

Villalba Cabello, F. (coord.), (2000): El sector agrario en Andalucía 1990-1999. Málaga.

\section{Informaciones de prensa}

\section{CAMBIO16}

7.11.1983, pp. 41-45: "La reforma de nunca acabar".

25.2.1985, pp. 48-50: "Reforma Agraria Andaluza. La tierra, para trabajarla".

DIARIO JAÉN

26.8.2006, p. 13: "Doscientos jornaleros toman una finca y exigen tierras para Jódar".

\section{EL PAÍS}

2.11.1983, p. 50: "El único camino, la reforma agraria integral".

4.11.1983, p. 85: "La reforma agraria andaluza: una necesidad política".

13.11.1983, p. 58: "Jornaleros contra máquinas en Andalucía".

29.2.1984, p. 44: "Declaraciones del hispanista Edward Malefakis: 'Andalucía no puede apostar su futuro a la agricultura"”.

20.12.1985, p. 59: "170.000 jornaleros no han conseguido trabajar los 10 días exigidos para cobrar desempleo".

26.6.1990, p. 21: "El hueso de la aceituna".

20.4.1994, p. 2: "Jornaleros andaluces anuncian una nueva campaña de ocupaciones de Fincas del Estado".

22.3.1998, p. 54: "Fischler, Garcíez y la marquesa".

31.1.1999, p. 30: "La finca es nuestra".

2.1.2001, p. 48: "40.000 personas abandonaron el sector agrario el año pasado".

3.7.2002, p. 22: "Los jornaleros andaluces marcharán hasta Madrid el día 11 "contra el decretazo". El Sindicato de Obreros de Campo ocupará "Fincas de terratenientes"”. 
21.10.2007, p. 34: "Las ayudas de la UE engordan las cuentas de grandes terratenientes". Süddeutsche Zeitung, Alemania

22.7.1980, p. 3: "Andalusien: Düsteres Schicksal hinter blendend weißen Fassaden. Das Spiel mit dem Feuer im Weizenfeld".

Triunfo

18.12.1976, pp. 42-46: "El resurgir campesino".

\section{Informaciones electrónicas}

Instituto Nacional de Estadística (2002a): Censo agrario 1999, "Resultados de Andalucía", 〈http://www.juntadeandalucia.es/institutodeestadistica/bd/censoagrario/caTab. jsp> (26.09.2006)

Instituto Nacional de Estadística (2002b): Censo agrario 1999, "Resultados nacionales, por comunidad autónoma y provincias", 〈http://www.ine.es/jaxi/tabla.do〉 (26.09.2006)

Fundación "Estrategias para el desarrollo económico y social del la provincia de Jaén" (2001), 〈http://www.ujaen.es/huesped/planestra/l/1c.html〉 (14.05.2004)

Noticias YA (28.8.2006): "El SOC anuncia nuevas ocupaciones de Fincas en octubre por parte de los jornaleros", «http://noticias.ya.com/local/andalucia/28/8/2006/socjornaleros-protesta.html> (26.09.2006)

\section{RESUMEN}

El artículo analiza el panorama estadístico de 507 fincas de gran y mediano latifundio. Se diferencian las superficies agrarias según sus aprovechamientos. Amén de las condiciones agrícolas, también se describen los comportamientos agro-sociales de los propietarios.

PAlabras Clave: finca; latifundio; latifundista; empresario agrícola; ICONA; campo secano; campo de regadío; olivo; Jaén.

\section{ABSTRACT:}

The article analyses the statistical panorama of 507 middle- and large-scale properties, differentiating the usable agricultural area according to the most important agricultural crops. In addition to the agricultural conditions, the agro-social behaviour of the proprietors is described.

KEY WORDS: Landed estate; large-scale landed property; great land owner; agrarian entrepreneur; ICONA; rain field; irrigation field; olive tree; Jaén. 
RÉSUMÉ:

Larticle analys le panorama statistique de 507 entreprises de propriété foncière moyennes ou importantes. Ce faisant, les surfaces agricoles utiles sont différenciées selon les plantes utiles les plus importantes. En dehors de ces conditions agricoles, l'article décrit aussi les comportements agraires-sociaux des propriétaires.

MoTS CLÉS: propriété foncière; propriété foncière importante; propriétaire terrien; entrepreneur agrarien; ICONA; culture pluviale; culture à irrigation; olivier, Jaén. 